\title{
The Social Conditions of Territorial Development: A Comparison between Sardinia and Sicily
}

\author{
Fiorella Vinci
}

Faculty of Psychology, University eCampus, Italy

Copyright (C) 2015 by authors, all rights reserved. Authors agree that this article remains permanently open access under the terms of the Creative Commons Attribution License 4.0 International License

\begin{abstract}
Through what mechanisms do social cognitive and normative dispositions of individuals help define the economic and social development of different territories? Placing itself within the tradition of the sociology of public action and making use of the results of a comparative study on the implementation of cohesion policy in Sicily and Sardinia, this paper suggests that the different reflexivity of public action found in the two regions could be conditioned by collective processes of individualization. The policies developed in the two regions differ for their degree of appropriateness to the economic and social history of their respective territories. The processes of individualization that enhance the dimensions of otherness and those of the limit, the legal and historical formations of individual autonomies seem to be the social mechanisms that could most of all affect the reflectivity of public action and the effectiveness of policies. The comparison reveals that the chronological anticipation of the processes of formation of private property and the social entrepreneurship role played by the local aristocracy following the unification of Italy led to the internalization of the legal sense of the limit and to that of the social need to regulate the lives of individuals in relation to others.
\end{abstract}

Keywords Political Morphologies, Reflexive Public Action, Individualization Process

\section{Introduction}

Parsonsian theories of modernization $[1,2]$ had a dual analytical ambition: to propose a historical-comparative interpretation of social development and - as Chazel [3] points out - to highlight the causal link between cultural and structural factors.

Successive transformations of the original theories - while having put the economic, political-institutional and cultural developmental factors into focus for example in the contributions by Eisenstadt [4] - have not always furthered the original analytic ambition.
Through what social mechanisms do cognitive and normative dispositions of individuals help define the economic and social development of different territories? And through which sociological methods is it possible to understand such mechanisms?

Placing itself within the tradition of the sociology of public action and making use of the results of a comparative study on the implementation of cohesion policy in Sicily and Sardinia [5], this paper analyses the main features of two distinct models of public action and highlights the social conditions of context which - as Duran explains [6],legitimize them.

The appropriation of the sociology of public action here proposed enhances the process dimension of sociological analysis. The questions asked relate to the promotion and the collective legitimization of different public policies and bring into focus the social conditions and institutional mechanisms that generate and legitimize different political morphologies.

As highlighted by Serravalli [7] realizing processes of institutional innovation in the regions of Southern Italy means, firstly and fundamentally, unlearning governance logics of a particularistic kind [8], admitting the existence of different kinds of logics [9], sharing their acceptance and striving to translate them into concrete public actions.

How are institutional processes of unlearning of particularistic political logics formed over time and which social mechanisms hold them back or on the contrary favour them?

In Sicily, the formation of a local development agency and its achievements in the implementation of cohesion policy are comprehensible in the light of standardized and occasional partnerships, established in the shadow of the dominant role assigned to the regional government and managed by local political figures [10].

In Sardinia, the history of an inter-municipal consortium and its ability to attract European Structural Funds, indicate partnerships which are selectively representative of local economic and political interests and signal the role played by the regional government in the promotion of cohesion policy as well as some sort of emulation mechanism of that role, 
inclusive of multiple interests and realized through the coordination of a variety of policies.

What contextual conditions in the two cases legitimize the formation of different partnership models [11] and, consequently, the formation of more innovative public actions in the case of Sardinia whilst of a more traditional kind in the case of Sicily?

In Sardinia, in the choices of the founding group of the consortium, a kind of reflexivity of political action can be identified [12] expressed by the search for policies that can not only be shared by the local community of reference but be considered acceptable by the community at large, representative of the local economic and social history and at the same time aimed at communicating this more broadly.

In Sicily, the public actions of a local development agency responsible for the implementation of cohesion policy signal the negotiations that take place between various interest groups. These negotiations, unlike those of the Sardinian consortium, appear less attentive to their collective acceptability and to the enhancement of their medium to long-term significance; as if in this regional context, at the collective level, there were moreover a greater dependence of political action on particularistic interests, and this kind of political regulation were legitimated by the reference population.

Could the contrasting reflexivity of political action found in the two cases result from different processes of formation of individualities not only of the political actors but more generally of the variety of social actors?

And if so, over time, what are the processes that in the two regions have legitimated different formations of individualities and what may today be the policies, which could fuel more reflexive political actions by impacting more markedly on the construction of individual autonomies?

The article is divided into two sections: the first is dedicated to the identification of the different political morphologies that in the two regions characterize the implementation processes of cohesion policy, the second to the sociological analysis of the genesis and processes of collective legitimation of different political morphologies.

\section{A Tactical Organisation: The Case of the Calatino South Simeto Local Development Agency}

The Calatino South Simeto local development agency does not pre-exist the implementation processes of structural funds but was established so as to facilitate access to them and their use. It is a political-territorial agency, created in fact by the alliance between several mayors, in other words by the confederation of several municipalities aiming to participate in EU tenders. Its establishment takes place in 1998 at the initiative of the Municipality of Caltagirone and from the political perspective appears to be an innovative project. The centre-left municipal administration which governed Caltagirone in those years sought to adopt new modalities for the securing of financial resources with respect to the previous ones. Formal arrangements and the establishment of a collective public player, consisting exclusively of political subjects and headed by the mayor of Caltagirone as municipal leader, replaced personal negotiations for regional and national funding of specific development projects. The establishment of the agency does not appear, however, in itself sufficient to establish new political modalities for intercepting funding. The political formation of the collective subject affects ab origine the territorial representation of interests whilst the asymmetry between the size of the Municipality of Caltagirone, the promoter of the agency and that of the other Municipalities creates from the outset a disproportion between this Calatinian municipality and the other member municipalities of the agency. The common goal of being able to benefit from the greatest amount possible of Community resources does not in itself appear sufficient to eliminate or resolve many latent organizational conflicts, as if the economic objective, in its generality, is not sufficient to promote a lasting political action. The organizational cohesion of the group appears to be hard to build; difficulties in identifying a territorial core business are the first signs of a troubled and difficult public action. Which development projects should one aim for? The identification of projects is one of the first obstacles to overcome, a consensus on a typology of projects, thus an agreement on a common idea of territorial development is replaced by a multiplicity of projects, promoted by different municipalities. The group is not able to interpret to the fullest the principle of coordination of the various public actions and of concentration of resources, key principles of Community law, reiterated strongly in the 2007-2013 legislation; the agency needs to survive and its internal cohesion is entrusted to a principle of municipal distribution of the resources and, consequently, of the projects.

The selection of the individuals responsible for planning and implementation suffers from the instrumental character of the cohesion of the group. The managers are appointed by the political organ of the agency and answer to it: their tasks are those of enforcement. The choice of a manager with specific technical skills and a personal idea of territorial development is replaced by a specialized manager who merely applies the development guidelines indicated by the political organs of the group. Also in this case, the group tends to try to maintain, day after day, its conditions of internal existence, the job of the technicians is to transform the different interests of the group into common interests. The request of exclusively executive tasks from the manager, on the one hand reveals the strong political imprint of the group: the agency has failed to transcend the interests of the various member municipalities and appears strongly conditioned by some political groups, on the other hand, it reveals the lack of a principle of differentiation operating within the group; the manager or the planning group do not 
place themselves as a separate entity that brings a different vision of the group and of the external environment but as the executor of the political will of the group. The closure of the group with respect to the external environment is also apparent from an analysis of the techniques of recruitment of internal staff. The agency's internal structure is composed of non-specialised personnel from the different municipalities. The internal organization of the group is based on non-permanent staff from which mainly executive tasks are requested. This staff does not appear inserted into specific training programs and complains, above all, about a state of disinformation regarding the activity of territorial development pursued by the agency.

\subsection{A Strategic Orientation: The case of the Sa Corona Arrùbia Tourism Consortium}

The Sa Corona Arrùbia tourism Consortium was not created in order to benefit from the structural funds but already existed when in the mid-90s the opportunity emerged to benefit from the funds. The establishment of the consortium in the early ' 80 s, and its legal and economic configuration, appropriate to implement the principle of partnership proposed by EU legislation, reveal processes of institutional learning and different logics of political action from those observed in the Sicilian case. "Here - as the mayor of Villanovaforru has recounted - we have learned to look at the possibilities offered by the European Union long before the Structural Funds, when the Fund for the South was still in force." ${ }^{1}$ The attention towards the European Union mentioned by the mayor arose from the need to realize a financially very demanding project, whose implementation, it was believed, would be facilitated by the involvement of several levels of government, from the provincial to the European. The identification of a specific project reveals itself as essential for the initiation of the whole process of funds provision. In the analysis of the process of participation in EU tenders, the choice of the consortium to build an archaeological museum not only appears earlier than subsequent choices but conditions not only the political but also the economic logics of local public action. From an economic point of view, the precise definition of a project sets the stage for the construction of a fundamental strategic orientation. From a political standpoint, since the beginning, this definition has the function of specifying and clarifying the formation of political action: the aim of the consortium is not the acquisition of financial resources, but the realization of a public utility, to which resource acquisition is instrumental.

In the analysis of the dynamics of collective action, the construction of an archaeological museum deserves further consideration. The political proposal to build a museum seems an innovative proposal, not only with respect to projects realised and / or in the pipeline in the north of the

1 Interview with the Mayor of Villanovaforru, one of the member municipalities of the Sa Corona Arrùbia tourism Consortium. island but also and above all, with respect to the creation of industrial parks so little consistent with family economic traditions, still essentially agri-pastoralist. The planning decision of the consortium shows awareness of the social plausibility of projects. As if not everything were feasible everywhere and as if there were specific contextual conditions for the development of a territory, based on the interdependence between the economic and social aspects. Moreover, the decision to build an archaeological museum has an added political value, it does not only appear accepted by the local community of reference but is communicable to the outside, it is a project shared by the community at large, suitable to represent to the outside a local story shared by the local population and at the same time novel.

\section{3. "Historicizing" and "Informal" Economic Practices: The case of the Calatino South Simeto Local Development Agency in Sicily}

Apparently, the projects for which funding is sought and which have been activated by the two political entities appear to be similar: the idea, in fact, of a kind of local development based on the enhancement of local cultural heritage appears in both projects and to such an extent as to constitute almost a recurring common leitmotif. The analysis of the two models of public actions, however, reveals many differences.

Simiand [13] at the beginning of the $20^{\text {th }}$ century, while hoping for some sort of integration of history in the shaping of the social sciences, was inviting scientists to refrain from proposing a historicizing history. For Simiand, historicizing history is a history that is not aware of the conditions from which it originated and with a tendency to reproduce itself.

The comparative analysis of the economic actions of the Calatino South Simeto agency in Sicily and those of the Sardinian consortium reveal, in the case of Sicily, economic practices that, in the footsteps of Simiand, can be defined as historicizing. The projects processed by the Calatino South Simeto agency are all based on the exploitation of local resources: natural and / or architectural resources, restoration of monuments and / or production of citrus fruit. The main difference with respect to the project initiatives undertaken by the Sardinian consortium is the inclusion of the various initiatives into specific economic logics. The enhancement of the local resource appears, in the case of the Calatino South Simeto agency, standardized, it does not correspond to an idea of local development which is defined, shared and consistent with the representations of development prevailing in the local community. The neglect of the economic importance of the tradition concerning the decoration of ceramics, widespread in the Calatino territory, signals, for example, the distance of the projects from the economic history in which one is operating. Not being able to find a core business for planning purposes that places the 
various economic initiatives in a wider territorial development project indicates that the group is not able to have an awareness of their own belonging to a specific social and economic context, which is characterized by specific availability of economic assets and has defined collective justifications for the use of such resources. In this situation, the agreements regarding the objectives reached by the group appear as agreements of purpose, particularly vulnerable to the particularistic tendencies emerging in the group and, above all, not suitable for achieving economic efficiency in the various initiatives. What is missing in this logic is the inclusion of the social in economic actions, which in the Sardinian consortium emerges from the attention paid to forms of economic development collectively considered more acceptable. The economic question that conveys the inclusion of the social in economic practices doesn't simply have the shape of what can be done with the available means, but, different and historical, of what can be done here and now with the available means. The inadequate consideration of the economic and social context in which one operates and in which the economic expectations of individuals are shaped causes a chain of perverse effects. The group - which cannot find an idea of development that cements its own cohesion in a stable and lasting manner - is constantly exposed to the risk of melt-down, continuously engaged in lengthy political mediation on the distribution of financial resources. The conventions, which in the case of the Sardinian consortium represent the institutionalization of specific forms of partnership and transform the oligarchic representation of the interests of the group in a more pluralistic representation, appear to be used by the Calatina agency in a standardized way. This type of use indicates, on the one hand the lack of confidence in their effective regulatory function, and on the other, the lack of conviction that effectively following them could enhance the efficiency of the economic practices of the group.

\section{1. "Historic" and "Conventional" Economic Practices: The case of the Sa Corona Arrùbia Tourism Consortium in Sardinia}

The comparative analysis of the cohesion of the two groups reveals in the Sardinian case the attention that the $\mathrm{Sa}$ Corona Arrùbia Consortium pays to the contextual conditions of territorial development. That group of friends who ask themselves about the future of young people in their own small towns, is a group that - using the language of Gauchet [14] one could say - relates to its own economic and social context in a historical manner and manages to assess available means in relation to the expected outcomes. The assessment carried out by the group of founders does not appear to be economic in the most reductive sense of the term but in a broader sense, it considers the collective plausibility of economic actions. The definition of ends and means is configured as a travail social as it is founded on the harmonization of the idea of development considered by the promoters as being well-attuned to the representations of development prevailing in the community.

Consequently, the design choices appear based on an idea of economic development that the local community considers possible. The social anchoring of design choices does not end with the selection of targets and means but continues in the processing and execution phases. The stratified character of the consortium reveals the involvement of the main centres of local interests. Equally, the involvement of local actors with increasingly more specialized functions in the implementation phases of the projects indicates economic practices open to the community and based on the activation of a kind of process of social cooperation. The spreading of formal conventions and their effective character as a regulatory instrument of inter-institutional relations mainly has the function of permitting social cooperation in time. The conventions, as a specification of the agreements reached, constantly actualise the pre-eminence of shared aims reducing the possibility of conflicts based on the defence of particularistic goals. There circulates among the founders a surprising trust in the efficacy of convention-based agreements. Not only are they constantly concerned about the maintenance of the group and believe that conventions can be the means to achieve partial agreements, but also believe that conventions can permit the realization of efficient economic actions. The collective legitimacy that pushes the consortium's group of founders towards these kinds of economic practices deserves some further reflection. How does it originate and how can it be modified? Does it stem solely from the condition of the founding political elite or does it also present specific contextual justifications? The awareness of its own possibilities for development and active participation in the resolution of common problems is not unusual in Sardinia, it has the shape of a collective political action and, frequently, as Cersosimo explains [15], also institutional. The history of the extraordinary intervention for the South in this region appears, from this point of view, exemplary. As reconstructed by Di Felice [16], "it is dotted with requests of modification of some interventions coming from the bottom, with interrogations and internal discussions at the Regional Assembly as well as in the central government." The debates often develop around the presentation and examination of economic data and derive, frequently, from research undertaken by various institutions: the regional commissions, the Chambers of Commerce and professional bodies. The anchoring of the debates on economic data removes them from being exclusively linked to political governance. On the one hand it gives such debates greater objectivity and, on the other hand, it brings out the common dimension that characterizes them. The regional formation since the early 90s of integrated territorial development systems, based on the formation of territorial institutional polyarchies, and based on contextual socio-economic analyses is another example of public actions not only based on forms of institutionalization of territorial partnership but also as noted by Chessa [17] on the value assigned to socio-economic analyses. 


\section{The Legal Significance of Processes of Individualization}

The comparative analysis of these two cases reveals different characteristics of public action. As Weber [18] had understood, it is not only the result of a conflicting composition of interests but results from the effort of composition in a defined historical time-period, it is therefore an economic action in relation to the consequences that flow from it in the short and medium to long term. Public actions that in the two cases characterize the implementation processes of cohesion policy appear different in relation to their economic significance. The aim of the activities of the Sardinian consortium is not only their effectiveness but their efficiency, in fact they have a medium to long term horizon. Their different temporal validity is related to their collective dimension, they do not aim at satisfying the needs of the political elite that is the promoter of such actions, but rather the different needs of the community understood in a broader sense. The efficiency of the public action of the Sardinian consortium, considered as a temporal medium to long term and broad social influence, coincides with the reflexivity of public action emphasized by Rosanvallon [19] but mainly appears to derive from the collective enhancement of the legal significance of the processes of individualization.

The political activities of the Sardinian consortium, especially if analysed over three decades, designate real political morphologies or political groups whose actions appear to be consistent with specific traditions and political cultures. The Sa Corona Arrùbia consortium shifts from economic policies based on mechanisms of imitation to policies based on mechanisms of emulation as it is able to enhance the economic significance of its actions. The work of enhancement does not appear isolated but appears very similar to that put in place by the regional government, it appears therefore as a shared political model. Its condition of possibility consists in representations of individualities which include otherness in their structuring and that from that inclusion moreover, shape the character which distinguishes their specificity or, wanting to use a Weberian [20] term, their honour.

The inclusion of otherness in the creation of individuality not only as a means of achieving personal goals but as an aim of being an individual, as a chance to identify oneself as a human being, constitutes the foundation of the processes of legitimation and dissemination of objective law. Political morphologies realised by the Sardinian consortium highlight the collective plausibility of being individuals in which the attention to the other is not restricted to family and / or social groups of belonging but are expanded to what Mead [21] defined as the generalised other. Such attention circumscribes the personal opportunities of action and, above all, allows the constant testing of the formation of individual representations, opens up the restricted communities of groups of belonging to other groups allowing the redefinition and the reinvention of local self representations. The rationality that establishes and develops the legal sense of the processes of individualization is one that we can define with Colliot-Thélène material [22], namely constantly in search of its own formation, of the composition of interests from which it derives.

The analysis of the Sicilian Calatino South Simeto agency displays different political morphologies. Here the mechanisms of imitation initiated by the agency fail to turn into mechanisms of emulation. Imitation does not assume a historical dimension, it is not applied to a specific we, it remains objective and as such a non-economic action.

The economic policies initiated by the agency are short-term policies, not supported by innovative political models which are shared at a regional level. Rather they are consistent with regional policy actions aimed at fuelling and reproducing the survival of a specific political class.

What strategies representative of the self collectively fuel political morphologies of this kind?

Essentially, they are defensive and self-referential strategies, in which the inclusion of otherness appears instrumental to the realization of particularistic interests. Here - the sense of honour of Weberian memory - does not coincide with the structural attention to the generalised other but rather coincides with the exclusion and in the limit the marginalization of the other that appears having the unique role of spectator and whose presence seems instrumental to the exhibition and celebration of the self.

Similar collective representations not only do not favour the formation and enhancement of economic actions in the sense described above but signal a modest enhancement of the legal significance of the processes of individualization. The collective justification of the limit - the foundation of objective law, in both its negative and positive dimensions, namely both as abstaining from ... or as a possibility of ... appears in this context not internalized, almost not constitutive of the definition of individualization. This condition emerges fundamentally from the impossibility of local actors to understand the subjective and local characters of their own social representations. The latter do not only appear impervious to the judgement of others but, above all, they end up influencing the structuring of processes of individualization. The enhancement of the legal significance of individuality appears to be a fundamental condition for the unlearning of particularistic logics of implementation of policy actions. It appears to be a fundamental precondition of politics, understood as a constant redefinition of interests involved and as consequent taking on of responsibility.

\section{The Contribution of a Process Analysis}

The hypothesis presented is derived from a process analysis. This operates by breaking down the social actions in search of their individual preconditions but at the same time constantly restoring the social significance of individual actions. The process perspective pulverises the apparent determinism of political morphologies in search of the 
historical roots of social actions, of those social facts which over time have made certain social representations and certain structuring of individuality more plausible and that, consequently, allow the researcher to understand the contextual significance of actions. Process analysis, understood in this sense, is a historical analysis, in our case, an analysis of the institutional histories of the two regions, an analysis of the formation and evolution of their regional autonomies. The uncovering of the enhancement of the economic significance of actions as the intermediate analytical moment that subsequently permits to understand the consequences of the legal significance of the processes of individualization is important because it outlines the different economic histories of the two regions. These are characterized, above all, after the unification of Italy and as documented by historians, by functions of the local aristocracy that are entrepreneurial in Sardinia and assisted in Sicily.

The comparison between the two regional histories highlights processes of disintegration of feuds as well as of varied and different formations of private property both in reference to their chronological order as well as in relation to their modalities of occurrence. The identification of such processes clarifies the legal significance of the processes of individualization and helps trace tracks of analysis relating to the promotion of those policies that can facilitate the formation of the legal significance of individualities.

If the right to property, as indicated by Locke [23], as well as in sociology for example by Durkheim [24] has had the function of establishing the collective plausibility of objective law and if the entrepreneurial role of the aristocracy - as indicated by Weber [25] - has allowed the renewal of the social order, then one can understand through which social mechanisms, in Sardinia historically, the legal significance of the processes of individualization has been legitimated. The chronological anticipation of the processes of formation of private property and the social entrepreneurship role played by the local aristocracy following the unification of Italy led to the internalization of the legal sense of the limit, the internalization of the social need to regulate the lives of individuals in relation to others and have spread collective justifications regarding the need to legally define-structure the individualities by establishing the almost analytical pre-eminence of objective law.

To the sociologist, the analysis of such social mechanisms, in addition to allowing an understanding of the differences in the contextual justifications of similar matters, also permits to select which other facts or rights may, currently and in some contexts, help to enhance the legal sense of the processes of formation of individualities.

Such an interpretation gives a different sense to cohesion policy and to coordination both between different levels of government as well as between different policies, as advocated by the current legislation on cohesion policy. The effectiveness and, above all, the efficiency of cohesion policy, is not only formed contextually but derives from the coordination between different policies (labour, tax, credit) and is a medium to long term process. Its effects or its failed implementation, does not consequently constitute only a waste of financial resources, but configures lost social development opportunities.

\section{Concluding Remarks}

Why do public policies have different consequences depending on the context in which they are activated? And what social mechanisms legitimate the selection and promotion of certain policies rather than others? The implementation of European cohesion policy, which formalizes homogeneous development ideas whilst being activated in national and regional contexts that are very heterogeneous between them, offers a good opportunity to understand the contextual mechanisms of social legitimation of public policies.

Using concepts and categories of analysis that are recurrent in the tradition of the sociology of public action and, more specifically, a sociological perspective that enhances process analysis of public action, this article emphasizes the logical-analytical continuity that exists between individualistic approaches and those defined as more holistic ones and suggests ways to achieve the policy innovations proposed by the European Union effectively in different social contexts. The comparative analysis of two distinct patterns of public action, for the implementation of cohesion policy activated in two regions of southern Italy, that is Sicily and Sardinia, provides an opportunity to highlight the social mechanisms of collective legitimation that fuel the two models and at the same time reveals the social effects of the enhancement of the legal significance of processes of formation of individualities.

The opportunity to interpret the political actions of the two subjects as political morphologies, that is, as public actions of specific political entities, deemed contextually valid by the local community of reference, expands the spectrum of analysis, bringing out not only the differences that exist between public actions implemented but also those, sometimes less obvious, between the social mechanisms that fuel them.

In the implementation of cohesion policy, the Sardinian Sa Corona Arrùbia tourism Consortium is able to identify a central development project, the construction of an archaeological museum, suitable to cement the internal cohesion of the consortium and at the same time to communicate to the local population itself as well as externally an image, a history of the territory different from the past. In realizing this project, as well the subsequent ones, the consortium resorts to formalized inter-institutional partnerships with other local authorities (Province and Region) and other economic and political institutions (Chambers of Commerce, banks).

The Sicilian Calatino South Simeto agency maintains the internal cohesion within its group by resorting to a sort of territorial distribution of development projects and, more 
specifically, a municipal one. The method used, while ensuring the survival of the group, does not define and does not communicate a shared and specific idea of development to the outside. The partnerships put in place, in relation to those established by the consortium, appear more standardized, more occasional and therefore less representative of the diversity of interests in the territory. The comparison puts into focus the different economic significance of the public actions taken by the two parties. Those carried out by the consortium enhance the search for efficiency by having a medium to long term horizon and by including the local community both in the selection of the public policies to be undertaken. The public actions effected by the Calatino South Simeto agency have a short-term scope and do not include the community of reference in the conception and implementation of policies, they seem to respond more to the particularistic needs of the promoting political elite.

The differences in the economic significance of public actions in the two contexts reveal heterogeneous political morphologies but they also reveal a different political reflexivity which signals a different political condition of individuals [26]. The modes of thinking and of acting that are considered to be contextually valid by individuals, highlight the function of the processes of individualization for the efficiency of public policies. Specifically, these modes contribute to put into focus the function of the enhancement of the legal significance of the social construction of individuality in territorial development processes. The analysis of the social consequences of the processes of individualization generated in the two contexts and of the historical facts that have favoured their formation allows one to explore the mechanisms of social legitimation of public law, reveals functions of policies not immediately imagined and helps understand the difficulties with which, in certain contexts, one may implement policy innovations proposed by the European Union. At the same time it also indicates the ways and policies through which it is possible to initiate real processes of both political and social innovation.

\section{REFERENCES}

[1] Parsons T, Le système des sociétés modernes, Biarritz, Dunod, 1973.

[2] Bendix R, Aspects of social change in modern Japan. Preconditions of Development: a comparison of Japan and Germany, Princeton University Press, 1967.

[3] Chazel F, La théorie analytique de la société dans l'œuvre de T. Parsons, Paris, Mouton, 1974.

[4] Eisenstadt S, Civiltà comparate: le radici storiche della modernizzazione, Napoli, Liguori, 1990.

[5] Vinci F, L'efficacia dei fondi strutturali europei. Processi e protagonisti al vaglio della sociologia dell'azione pubblica, Milano, Franco Angeli, 2013.

[6] Duran P, Penser l'action publique, Paris, L.G.D.J, 1999.

[7] Serravalli G, Né facile, né impossibile. Economia e politica dello sviluppo locale, Roma, Donzelli, 2006.

[8] Ascoli U, Il welfare in Italia, Bologna, Il Mulino, 2011.

[9] Leonardi R, Nanetti R, Effetto Regione in Basilicata. Le sinergie dello sviluppo, Milano, Franco Angeli, 2010.

[10] La Spina A, Ambizioni e insuccessi di alcune politiche di sviluppo locale per il Mezzogiorno, Patti Territoriali e Programmi Integrati Territoriali, Quaderni di Sociologia, 48, 2009.

[11] Profeti S, Il potere locale tra politica e politiche. Il mosaico della governance nell'area vasta fiorentina, Soveria Mannelli, Rubbettino, 2010.

[12] Rosanvallon P, La légitimité démocratique. Impartialité, réflexivité, proximité, Paris, Seuil, 2008.

[13] Simiand F, Critique sociologique de l'économie, Paris, PUF, 2006.

[14] Gauchet M, La condition politique, Paris, Gallimard, 2005.

[15] Cersosimo D, Dai Patti ai PIT. Lezioni dall'esperienza, in Deidda D. (ed.), Governance e Sviluppo Territoriale, Rome, Formez, 2004.

[16] Di Felice M L, La storia economica dalla fusione perfetta alla legislazione speciale, in Berlinguer L.,Mattone A., Storia d'Italia. Le Regioni dall'Unità a Oggi. La Sardegna, Torino, Einaudi, pp. 291-324, 1998.

[17] Chessa $\mathrm{O}$, La specialità sarda e il federalismo asimmetrico, Rivista giuridica del Mezzogiorno, n. 1/2011, pp. 553-574, 2011.

[18] Weber M, Economia e Società, Vol. I, II, III, IV, Milano, Edizioni Comunità, 1999-2000.

[19] Rosanvallon P, La légitimité démocratique. Impartialité, réflexivité, proximité, Paris, Seuil, 2008.

[20] Weber M, L'éthique protestante et l'esprit du capitalisme, Paris, Gallimard, 2003.

[21] Mead J.H., Mente, sé e società, Firenze, Giunti Editore, 2010.

[22] Colliot-Thélène C, Etudes wébériennes. Rationalités, histoires, droits, Paris, PUF, 2001.

[23] Locke J, Traité du gouvernement civil, Paris, Garnier Flammarion, 1984.

[24] Durkheim E, Leçons de sociologie, Paris, PUF, 1997.

[25] Weber M, Economia e società. La città, Roma, Donzelli, 2006.

[26] Gauchet M, La condition politique, Paris, Gallimard, 2005. 